\title{
Evaluation of Lisianthus as an Indicator Host for Iris yellow spot virus
}

Rajagopalbabu Srinivasan, Stan Diffie, and Sivamani Sundaraj, Department of Entomology University of Georgia, Tifton 31793; Stephen W. Mullis, Department of Plant Pathology, University of Georgia, Tifton 31793; David Riley, Department of Entomology, University of Georgia, Tifton 31793; Ron Gitaitis, Department of Plant Pathology, University of Georgia, Tifton 31793; and Hanu R. Pappu, Department of Plant Pathology, Washington State University, Pullman 99164

\begin{abstract}
Srinivasan, R., Diffie, S., Sundaraj, S., Mullis, S. W., Riley, D., Gitaitis, R., and Pappu, H. R. 2011. Evaluation of Lisianthus as an indicator host for Iris yellow spot virus. Plant Dis. 95:1520-1527.

Iris yellow spot virus (IYSV) can severely affect onion production. IYSV is transmitted by the onion thrips, Thrips tabaci. However, information on IYSV-thrips-onion interactions is limited due to the difficulty associated with infecting onion plants experimentally. Lisianthus (Eustoma russellianum) was used as an indicator host to study mechanical transmission of IYSV, IYSV transmission by T. tabaci, IYSV distribution in the host plant, and the effect of temperature on IYSV symptom expression. Mechanical inoculation tests from IYSV-infected onion plants to noninfected lisianthus plants resulted in a mean transmission rate of $82.5 \pm 6.9 \%$ (mean \pm standard error), and from IYSV-infected lisianthus plants to noninfected lisianthus plants re-

transmitted IYSV at a rate of $80.0 \pm 8.3 \%$ from infected onion plants to noninfected lisianthus plants. To assess IYSV distribution in infected lisianthus plants, leaf sections, stems, and roots were tested by enzyme-linked immunosorbent assay (ELISA). All the plant parts tested positive for IYSV, but not on every plant assayed. Alternating night and day temperatures of 18 and $23^{\circ} \mathrm{C}, 25$ and $30^{\circ} \mathrm{C}$, and 30 and $37^{\circ} \mathrm{C}$ were evaluated for the effects on IYSV symptom expression. More severe symptoms developed on inoculated plants incubated at the 18 and $23^{\circ} \mathrm{C}$ or 25 and $30^{\circ} \mathrm{C}$ temperature regimes than at the 30 and $37^{\circ} \mathrm{C}$ regime, and symptoms were observed earliest on plants incubated at the 25 and $30^{\circ} \mathrm{C}$ temperature regime compared to the other temperature regimes.
\end{abstract} sulted in a mean transmission rate of $89.2 \pm 7.1 \%$. T. tabaci adults
Thrips-transmitted Iris yellow spot virus (IYSV; Family Bunyaviridae; Genus Tospovirus) can cause severe yield losses in onion (Allium cepa L.) bulb and seed crops (6). The virus is also reported to infect other Alliaceae members, such as garlic ( $A$. sativum L.), leek (A. porrum L.), and chive (A. schoenoprasum L.) (6). Some tospoviruses are transmitted by more than one thrips species $(18,29,30)$; however, to date, IYSV is only known to be transmitted by onion thrips (Thrips tabaci (Lindeman)) (Thysanoptera: Thripidae) (10). In spite of the economic importance of IYSV in onion, limited information on IYSV-thrips-onion interactions is currently available. This can be attributed, in part, to the narrow host range of IYSV compared to other tospoviruses, such as Tomato spotted wilt virus (TSWV) and Impatiens necrotic spot virus (INSV), and to the fact that IYSV was only relatively recently described $(4,23,28)$.

TSWV is the most studied Tospovirus species $(22,23,28-30)$. TSWV-thrips-plant host interactions have been well characterized due, in part, to the availability of numerous indicator hosts for TSWV, such as Datura stramonium L., Emilia sonchifolia L., Nicotiana benthamiana Domin., and Petunia hybrida Vilm. $(2,7,18,19,31-33)$. Studies using mechanical and thrips inoculations on these hosts have provided important insights into symptom expression, virus distribution, virus biological diversity, and thripsTSWV interactions (13-15,31-33). Mechanical inoculations have been used routinely to distinguish biologically distinct TSWV isolates (strains) and the interactions of these strains with different host plants (13-15). Studies with indicator hosts such as $P$. hybrida, N. benthamiana, D. stramonium, and N. tabacum L. have led to development of bioassays that are routinely used to assess vector transmission parameters, such as latent period, transmission

Corresponding author: Rajagopalbabu Srinivasan,

E-mail: babusri@uga.edu

Accepted for publication 29 June 2011.

doi:10.1094/PDIS-06-10-0473

(c) 2011 The American Phytopathological Society period, and vector competence (18,19,31-33). Similarly, a number of indicator hosts for INSV have been identified and are used to assess INSV-host plant interactions and INSV-thrips interactions $(27,31,33)$.

IYSV interactions with plant hosts and the thrips vector, in comparison to TSWV, are not well characterized. In addition to the reasons stated above, this is due in part to the lack of an efficient mechanical inoculation procedure to infect onion with IYSV (1). Using mechanical inoculation, Bag and Pappu (1) recently described the responses of a number of indicator hosts to IYSV infection and documented the types of symptoms on each host. Pepper (Capsicum annuum L.), Inca wheat (Chenopodium quinoa Wild.), Jimson weed (D. stramonium L.), and cowpea (Vigna unguiculata L.) were shown to produce local lesions following IYSV infection. Lisianthus (Eustoma russellianum Salisb.) was identified as a host for IYSV in the Besor area of Israel by Kritzman et al. (9), who confirmed IYSV infection of lisianthus and characterized IYSVinduced symptoms on this host. IYSV typically produced necrotic spots and rings on leaves, and eventually caused systemic necrosis $(9,10)$. In this study, we used lisianthus as an indicator host to characterize IYSV-thrips-host plant interactions through mechanical and thrips inoculations. The objectives of this study were to develop an indicator host model system to evaluate IYSV isolates, and assess thrips transmission efficiency of IYSV to lisianthus. We compared both mechanical and thrips transmission of IYSV to lisianthus from infected onion and lisianthus plants, and monitored symptom expression and virus distribution within the inoculated lisianthus plants. IYSV transmission assays were developed using single leaves and leaf disks of lisianthus. In addition, because environmental parameters such as temperature are known to play an important role in TSWV and INSV symptom expression on various host plants $(11,12,15,25,26)$, we evaluated the effect of temperature on IYSV symptom expression in lisianthus. Transmission assays were conducted at different alternating night and day temperatures, and symptom expression was monitored. Furthermore, IYSV-induced symptoms on lisianthus were compared to those caused by TSWV on lisianthus to validate the use of this plant species as an indicator host for IYSV. 


\section{Materials and Methods}

Host plants and IYSV isolate. Lisianthus seedlings ('ABC' series) provided by Speedling Inc. were used for all the experiments. Two- to three-week-old seedlings were planted in $10 \mathrm{~cm}$ diameter $\times 8 \mathrm{~cm}$ tall pots (Hummert International) in a commercial potting mix (Sunshine LP5 Plug Mix, Sun Gro Horticulture Industries) and maintained at 25 to $30^{\circ} \mathrm{C}$ and 80 to $90 \% \mathrm{RH}$ with a 14-h photoperiod in a greenhouse in thrips-proof cages, each $47.5 \mathrm{~cm}^{3}$ (Megaview Science Co.). Onion seedlings of the cultivar Pegasus (Monsanto Vegetable Seeds) were grown from seeds planted into pots and maintained in thrips-proof cages as described for lisianthus plants. A local IYSV isolate from Georgia, likely introduced from Peru $(16,21)$, was used in this study.

Maintenance of onion thrips (T. tabaci). Onion thrips were initially collected from onion plants in Reidsville, GA in 2006. Voucher specimens of $T$. tabaci are maintained at the Georgia Museum of Natural History, University of Georgia, Athens. Nonviruliferous and potentially viruliferous thrips were maintained separately on onion plants at the Coastal Plain Experiment Station, University of Georgia, Tifton. Nonviruliferous T. tabaci were maintained on noninfected onion plants under the conditions described above. Potentially viruliferous thrips were maintained similarly in a different greenhouse on IYSV-infected onion plants. Thrips colonies were thelytokous in nature (20). A majority $(>95 \%)$ of individuals in the colonies were female, and therefore female thrips were used predominantly in transmission experiments. New onion seedlings were added as required to maintain the thrips colonies.

Mechanical inoculation of lisianthus plants with IYSV. Mechanical inoculations were initially performed using whole lisianthus plants (approximately $10 \mathrm{~cm}$ tall, with 10 leaves). Inoculations were conducted from IYSV-infected onion plants to noninfected lisianthus plants and also from IYSV-infected lisianthus plants to noninfected lisianthus plants. Ten plants were used for each type of inoculation. Each plant was considered a replicate. The experiment was repeated three more times with 15,10 , and 15 plants, respectively ( $n=50$ plants for all four repeats of the experiment). The number of plants for each experiment varied based on the availability of lisianthus plants of the same size and age. Treatments were assigned to plants using a completely randomized design.

Mechanical inoculations were performed as described by Mandal et al. (13). One hundred milligrams of symptomatic, young leaf tissue (sampled approximately 2 to 3 weeks postinoculation from 50-day-old onion plants and 40-day-old lisianthus plants) were ground in liquid nitrogen, to which $0.1 \mathrm{M}$ phosphate buffer $(\mathrm{pH}$ 7.0, containing $1.7 \%$ potassium phosphate dibasic, $1.4 \%$ potassium phosphate monobasic, $0.2 \%$ sodium sulfite, and $0.01 \mathrm{M}$ mercaptoethanol) was added. Celite 545 (Acros Organics) and an abrasive Carborundum (320 grit, Fisher Scientific) were each added at 0.01 $\mathrm{g} / \mathrm{ml}$ of buffer. IYSV-infected onion or lisianthus leaf tissue was used for inoculation depending on the treatment. The adaxial surfaces of fully expanded leaves of lisianthus plants were inoculated with approximately $0.1 \mathrm{ml}$ of inoculum for each leaf, and inoculated plants were placed in thrips-proof cages under the conditions mentioned above. The same number of lisianthus plants was mechanically inoculated with ground tissue of noninfected onion leaves or noninfected lisianthus leaves. Lisianthus plants inoculated with noninfected onion leaves or noninfected lisianthus leaves served as two negative control treatments.

Symptom development was monitored daily, and IYSV infection in foliage was detected using antibodies specific to the IYSV nucleocapsid protein by double antibody sandwich enzyme-linked immunosorbent assay (DAS-ELISA) (Agdia Inc.) 2 to 3 weeks postinoculation (3). At the time of testing, the inoculated plants typically were $15 \mathrm{~cm}$ tall (approximately 50 days old) and had at least 15 nodes. To assess IYSV infection in each leaf sample, a positive threshold of the mean absorbance at $405 \mathrm{~nm}$ plus four standard deviations was used, and this threshold was calculated for each microtiter plate. IYSV infection in a total of 10 ELISA-positive samples from the four repeats of this experiment was confirmed using reverse transcriptase polymerase chain reaction (RTPCR) with nucleocapsid gene (N-gene)-specific primers (21). The approximately 700-bp amplicon was sequenced and compared by pairwise alignment with the original isolate sequence as described by Nischwitz et al. (21).

Statistical analysis was done to compare the efficiency of mechanical inoculations from IYSV-infected onion plants to noninfected lisianthus plants and from IYSV-infected lisianthus plants to noninfected lisianthus in each experiment. Treatment was considered a fixed effect, and replication was considered a random effect. IYSV infection status was treated as a binomial response (positive or negative), and statistical differences among treatments were estimated using Proc GENMOD with the logit link function in SAS at $\alpha=0.05$ (SAS Institute).

Mechanical inoculation of onion plants with IYSV. Similar to the lisianthus mechanical inoculations described for the previous experiment, 30-day-old onion seedlings were mechanically inoculated with IYSV-infected onion leaf tissue and IYSV-infected lisianthus leaf tissue. Ten plants were used for each type of inoculation (onion to onion and lisianthus to onion). The experiment was repeated three times with 15,10 , and 15 onion seedlings, respectively, for each type of inoculation. Each plant was considered a replicate. The same number of onion plants $(n=10$ or 15$)$ inoculated with noninfected onion or lisianthus leaf tissue served as the two negative control treatments in each experiment. Inoculated onion plants were placed in thrips-proof cages, and IYSV infection was determined by DAS-ELISA as described for lisianthus. Treatments were assigned to plants using a completely randomized design. Statistical analysis was done to compare the efficiency of mechanical inoculations from IYSV-infected onion to onion and from IYSV-infected lisianthus to onion, as described above.

Mechanical inoculation of lisianthus plant sections with IYSV. The suitability of lisianthus plant sections for IYSV infection and the potential to develop plant tissue-based bioassays for IYSV studies using lisianthus stem cuttings, individual leaves, and leaf disks was explored. Stem cuttings (approximately 5 to $7 \mathrm{~cm}$ long) with apical buds were clipped from 10- to $15-\mathrm{cm}$-tall lisianthus plants, fully expanded single leaves were handpicked from the upper portion of the plants, and leaf disks of $15 \mathrm{~mm}$ diameter were cut from individual leaves with a cork borer. Lisianthus plant sections ( $n=20$ for each plant part) were mechanically inoculated using IYSV-infected lisianthus leaf tissue as the inoculum. Adaxial surfaces of fully emerged leaves on stem cuttings, individual leaves, and leaf disks were mechanically inoculated as described for whole plants. One milliliter of buffer containing inoculum was used to inoculate approximately two stem cuttings and 10 leaves or leaf disks. This experiment was repeated two times $(n=$ total of 60 for each plant part for all three repeats of the experiment).

Stem cuttings were held in 20-ml clear scintillation vials (potassium-free, borosilicate glass vials, Fisher Scientific) filled with tap water. Inoculated leaves were placed in a petri dish (one leaf per petri dish) lined with a moistened filter paper (Grade 1, Whatman) and sealed with laboratory film (Parafilm). Leaf disks were placed in tap water ( $2 \mathrm{~mm}$ depth) in multiwell culture plates (Corning) at the rate of 20 leaf disks per culture plate. All the inoculated sections were held at $24^{\circ} \mathrm{C}$ for 1 to 2 weeks postinoculation. Treatments were assigned to plant sections using a completely randomized design. IYSV infection was determined by DASELISA as explained above. The same number $(n=20$ for each repeat of the experiment) of lisianthus stem cuttings, leaves, and leaf disks inoculated with noninfected lisianthus leaf tissue served as negative control treatments. Statistical analysis was performed to evaluate differences in IYSV infection rates among various plant sections tested, as described above. Differences among treatments were estimated using Proc GENMOD in SAS. Also, SAS was used to calculate orthogonal contrasts (5) to evaluate differences between treatment pairs based on analysis of variance at $P=0.05$. 
IYSV distribution in lisianthus plants. IYSV distribution in lisianthus plants mechanically inoculated with IYSV-infected lisianthus leaf tissue was determined using plants that tested positive for IYSV by DAS-ELISA. Ten plants were used in the first experiment, and each plant was considered a replicate. This experiment was repeated three times with 13,10 , and 15 plants, respectively. Five samples from each plant were tested for IYSV using DAS-ELISA, including leaf samples from the upper, middle, and lower portions of each plant, as well as stem and root portions from each plant. Lisianthus plants at the time of testing had approximately 15 nodes (five nodes in each section: upper, middle, and lower). In general, symptomatic parts were selected from each section, when observed. Each plant section was considered a treatment. Based on the completely randomized design, differences in incidence of IYSV infection among plant parts were evaluated using Proc GENMOD. The statistical significance of differences between treatment pairs was estimated using orthogonal contrasts at $P=0.05$.

Mechanical inoculation of lisianthus plants with TSWV. TSWV is another Tospovirus that commonly affects some Alliaceae members, and is transmitted by thrips (16). Given that TSWV-infected lisianthus plants might exhibit symptoms similar to those caused by IYSV, mechanical inoculations of lisianthus with TSWV were performed as described above for IYSV using whole lisianthus plants. Symptomatic foliar tissue from the upper portion of TSWV-infected tobacco plants (cultivar NC 2326), sampled 2 weeks dpi, was used as the inoculum. TSWV-infected tobacco plants were generated by mechanical inoculation. Mechanical inoculation was performed as described by Mandal et al. (13). A local TSWV isolate collected from tobacco was used in this study. Ten lisianthus plants were used for this experiment, and each plant was considered a replicate. This experiment was repeated three times with 11,10 , and 10 plants, respectively. In each repeat of the experiment, the same number of lisianthus plants inoculated with noninfected tobacco leaf tissue served as the negative control treatment. Symptoms were monitored daily and infection status was verified using TSWV nucleocapsid gene-specific antibodies by DAS-ELISA (Agdia) 2 to 3 weeks postinoculation, as described above for IYSV. The treatments were assigned to plants using a completely randomized design and the incidence of TSWV infection $(\%)$ was estimated.
Thrips-mediated inoculation of lisianthus plants with IYSV. Lisianthus seedlings were used for thrips transmission assays. $T$. tabaci adults that developed on IYSV-infected onion plants were transferred to noninfected lisianthus plants using a paint brush (fine camel hair \#2 with aluminum ferrules, Charles Leonard Inc.) and enclosed in a Mylar film cage (Grafix) with a copper mesh top (mesh pore size of $170 \mu \mathrm{m}$ ) (TWP). A total of 10 plants was used for this experiment, each plant was considered a replicate, and the experiment was repeated four times with 10 plants in each repeat. Each plant was inoculated with 10 potentially viruliferous $T$. tabaci adults taken from IYSV-infected onion plants. Nonviruliferous $T$. tabaci adults from noninfected onion plants were transferred to noninfected lisianthus plants (10/plant) and served as the negative control treatment. Inoculated plants were monitored for IYSV symptoms daily and tested for IYSV by DAS-ELISA 2 to 3 weeks postinoculation. The treatments were assigned to plants using a completely randomized design, and the incidence of IYSV infection $(\%)$ was estimated.

IYSV symptom expression on inoculated lisianthus plants incubated at different diurnal temperature ranges. Growth chambers (Intellus Environmental Controller 13.6 LLVL, Percival Scientific, Inc.) were used to evaluate three diurnal temperature ranges (alternating night and day temperatures, with lower temperature at night and higher temperature at day) on IYSV infection of lisianthus under a 12-h day length at 80 to $90 \% \mathrm{RH}: 18$ and $23^{\circ} \mathrm{C}, 25$ and $30^{\circ} \mathrm{C}$, and 30 and $37^{\circ} \mathrm{C}$. The temperature ranges were chosen based on previous studies $(15,25,26)$. Ten lisianthus seedlings were mechanically inoculated for each temperature range using IYSVinfected lisianthus leaf tissue. Each plant was considered a replicate. This experiment was repeated three times with 10 lisianthus seedlings used for each treatment in each repeat of the experiment. Ten lisianthus plants inoculated with noninfected lisianthus leaves served as the negative control treatment for each temperature range in each repeat of the experiment. A split-plot design was utilized for this experiment with temperature ranges assigned to main plots (incubators) and inoculation treatments (with noninfected versus IYSV-infected lisianthus tissue) assigned to split plots. Symptoms were monitored daily, and incidence (\%) of plants with IYSV infection at each diurnal temperature range was determined using DAS-ELISA. The statistical significance of the incidence of IYSV

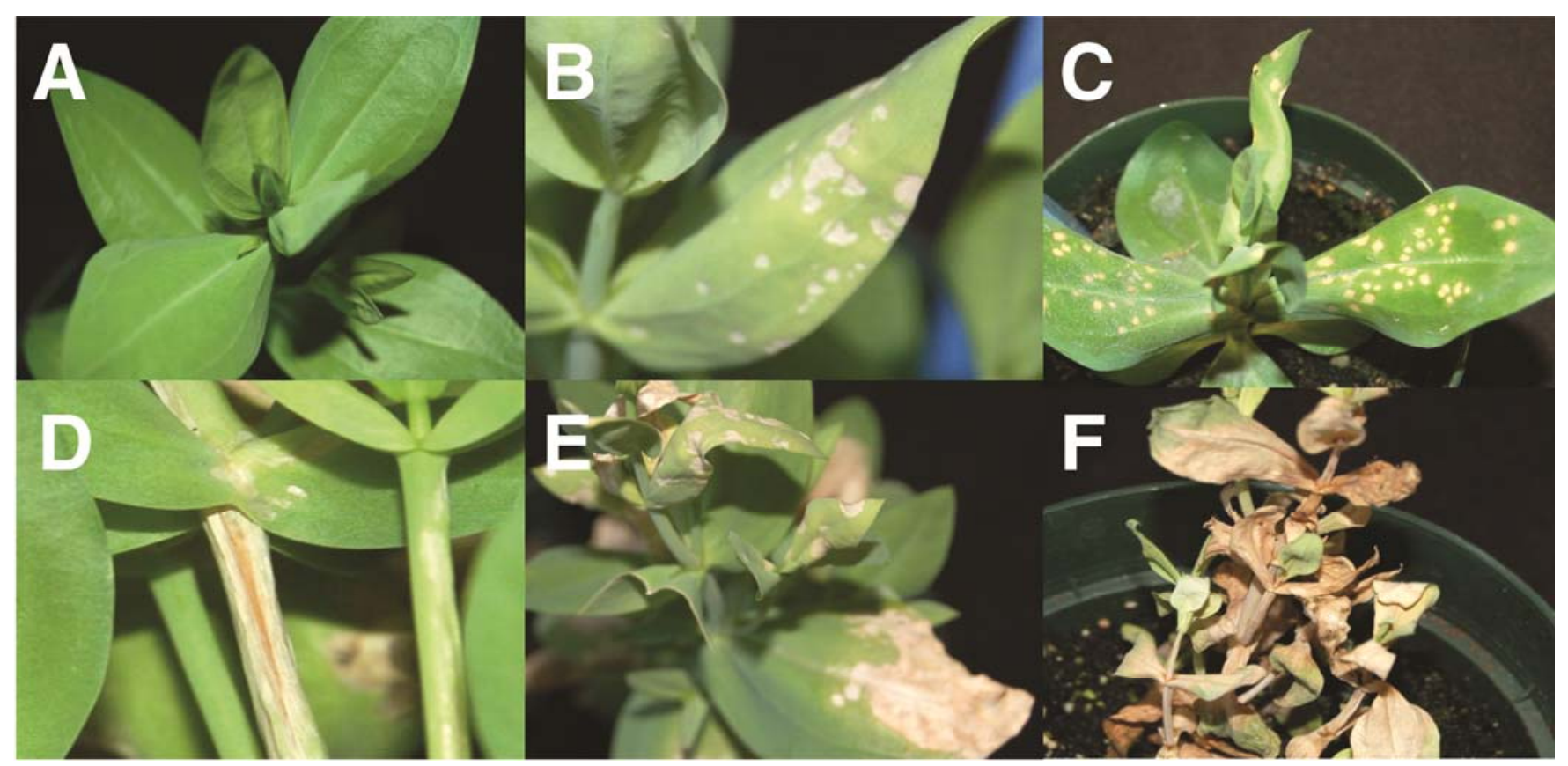

Fig. 1. Symptoms of Iris yellow spot virus (IYSV) infection on lisianthus plants: A, noninfected plant; B, sunken spots observed 3 to 5 days postinoculation (dpi); C, necrotic spots observed 6 to 8 dpi; D, stem necrosis and/or flecking observed 10 to 15 dpi; E, systemic infection observed 15 to 20 dpi; and F, dead plants observed 28 to 30 dpi. Approximately 10-cm-tall lisianthus plants were mechanically inoculated using IYSV-infected lisianthus or onion leaves as inoculum, as shown in B to F, or with noninfected lisianthus or onion leaves for the control treatment, as shown in A. 
infection in control plants and IYSV-inoculated plants at each diurnal temperature range was assessed using Proc GENMOD. The statistical significance of differences between treatment pairs were estimated using orthogonal contrasts at $P=0.05$.

\section{Results}

Mechanical inoculation of lisianthus plants with IYSV. Lisianthus plants inoculated with IYSV-infected onion or lisianthus foliage produced symptoms (Fig. 1). Sunken spots developed on the foliage 3 to 5 days postinoculation (dpi) (Fig. 1B), and the spots turned necrotic 6 to 8 dpi (Fig. 1C). Necrotic spots and/or flecking were also observed on lisianthus stems (Fig. 1D). Subsequently, the spots coalesced, symptoms spread throughout the plant (Fig. 1E), and the virus infection killed most of the infected plants approximately 30 dpi (Fig. 1F). No such symptoms were observed on lisianthus plants inoculated with noninfected lisianthus tissue and/or noninfected onion tissue in all repeats of this experiment (Fig. 1A).

The RT-PCR assays of 10 plants that tested positive for IYSV by ELISA produced a 700-bp amplicon for each of the 10 plants, confirming the IYSV infection status of each plant. Sequences of 4 of the 10 amplicons were submitted to GenBank (HM453886 to HM453889). Pairwise alignments were used to compare these four partial IYSV N-gene sequences from the inoculated lisianthus plants with those in GenBank. Comparisons indicated that IYSV $\mathrm{N}$-gene sequences were 98.9 to $100 \%$ identical and were 98.3 to $99.5 \%$ identical to isolates of IYSV previously reported from Georgia (DQ838591 to DQ838594). Statistical analysis of results from each repeat of the experiment did not reveal any significant differences in IYSV-infection rates in lisianthus plants inoculated with IYSV-infected lisianthus tissue versus IYSV-infected onion tissue (Table 1). Mechanical inoculation of lisianthus plants with IYSV-infected lisianthus tissue resulted in a mean infection incidence of $89.2 \pm 7.1 \%$ (mean \pm standard error), and a mean infection incidence of $82.5 \pm 6.9 \%$ was detected when IYSV-infected onion tissue was used as the inoculum source (Table 1).

Mechanical inoculation of onion plants with IYSV. Symptoms typical of IYSV infection were not found on onion plants inoculated with noninfected lisianthus and noninfected onion tissue in any repeats of the experiment. IYSV infection rates (incidence of plants infected with IYSV) in onion did not differ significantly in all the repeats of the experiment when inoculated with IYSV-infected lisianthus tissue versus IYSV-infected onion tissue (Table 1). Mechanical inoculation of onion seedlings with IYSV-infected onion leaf tissue did not result in any IYSV infection (Table 1). Inoculation of onion seedlings with IYSV-infected lisianthus leaf tissue resulted in a very low incidence of IYSV infection of $1.7 \pm$ $1.7 \%$ (mean \pm standard error) (Table 1).

Mechanical inoculation of lisianthus plant sections with IYSV. Mechanical inoculations of IYSV onto stem cuttings, single leaves, and leaf disks of lisianthus also produced similar sunken spots as seen on inoculated whole plants of lisianthus 3 to $5 \mathrm{dpi}$ (Fig. 2). IYSV transmission rates varied among the lisianthus plant

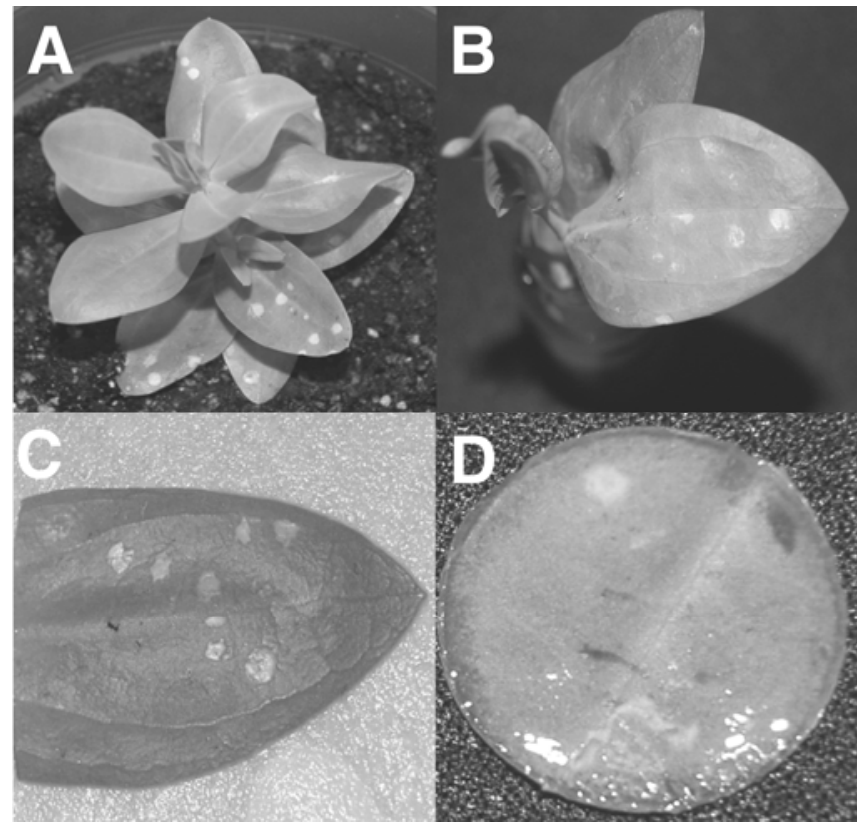

Fig. 2. Iris yellow spot virus (IYSV) symptom expression on: $\mathbf{A}$, a whole lisianthus plant; B, a stem cutting; C, a single leaf; and D, a leaf disk of lisianthus. Stem cuttings (approximately 5 to $7 \mathrm{~cm}$ long) with apical buds were clipped from $15-\mathrm{cm}$ tall lisianthus plants; single leaves were obtained from the upper portion of lisianthus plants; and leaf disks $15 \mathrm{~mm}$ in diameter were cut from individual leaves of lisianthus plants. Adaxial surface of fully expanded leaves on stem cuttings, and upper surfaces of leaves and leaf disks were mechanically inoculated as described in the text. Symptoms appeared 3 to 5 days postinoculation. IYSV infection in each plant section was verified using double antibody sandwich enzyme-linked immunosorbent assay (DAS-ELISA) 1 to 2 weeks postinoculation.

Table 1. Iris yellow spot virus (IYSV) transmission to lisianthus using mechanical inoculation from IYSV-infected onion or lisianthus plants

\begin{tabular}{|c|c|c|c|c|c|}
\hline \multirow{2}{*}{$\begin{array}{l}\text { Experiment and mechanical inoculation } \\
\text { (source plant to inoculated plants) }\end{array}$} & \multicolumn{4}{|c|}{ Number of plants infected/inoculated ${ }^{\mathrm{w}}$} & \multirow[b]{2}{*}{ Incidence (\%) of infected plants } \\
\hline & $\mathbf{I}$ & II & III & IV & \\
\hline \multicolumn{6}{|l|}{ Inoculation of lisianthus plants } \\
\hline IYSV-infected onion to lisianthus ${ }^{y}$ & $7 / 10$ & $11 / 15$ & $10 / 10$ & $13 / 15$ & $82.5 \pm 6.9$ \\
\hline Noninfected onion to lisianthus ${ }^{\mathrm{y}}$ (control) & $0 / 10$ & $0 / 15$ & $0 / 10$ & $0 / 15$ & 0 \\
\hline IYSV-infected lisianthus to lisianthus ${ }^{\mathrm{y}}$ & $7 / 10$ & $13 / 15$ & $10 / 10$ & $10 / 15$ & $89.2 \pm 7.1$ \\
\hline Noninfected lisianthus to lisianthus ${ }^{\mathrm{y}}$ (control) & $0 / 10$ & $0 / 15$ & $0 / 10$ & $0 / 15$ & 0 \\
\hline \multicolumn{6}{|c|}{ Proc GENMOD type 3 analysis: Onion to lisianthus vs. lisianthus to lisianthus } \\
\hline$\chi^{2}$ & 0.00 & 1.72 & $\mathrm{NE}$ & 2.94 & \\
\hline$P>$ chi-square & 1.0000 & 0.1893 & $\mathrm{NE}$ & 0.0866 & \\
\hline \multicolumn{6}{|l|}{ Inoculation of onion plants } \\
\hline IYSV-infected onion to onion ${ }^{y}$ & $0 / 10$ & $0 / 15$ & $0 / 10$ & $0 / 15$ & 0 \\
\hline Noninfected onion to onion ${ }^{y}$ (control) & $0 / 10$ & $0 / 15$ & $0 / 10$ & $0 / 15$ & 0 \\
\hline IYSV-infected lisianthus to onion ${ }^{y}$ & $0 / 10$ & $0 / 15$ & $0 / 10$ & $1 / 15$ & $1.7 \pm 1.7$ \\
\hline Noninfected lisianthus to onion ${ }^{y}$ (control) & $0 / 10$ & $0 / 15$ & $0 / 15$ & $0 / 15$ & 0 \\
\hline \multicolumn{6}{|c|}{ Proc GENMOD type 3 analysis: Onion to onion vs. lisianthus to onion } \\
\hline$\chi^{2}$ & $\mathrm{NE}^{\mathrm{z}}$ & $\mathrm{NE}$ & $\mathrm{NE}$ & 0.00 & \\
\hline$P>$ chi-square & $\mathrm{NE}$ & NE & $\mathrm{NE}$ & 1.0000 & \\
\hline
\end{tabular}

${ }^{\text {w}}$ Inoculated plants were tested for IYSV infection by double antibody sandwich enzyme-linked immunosorbent assay (DAS-ELISA) 2 to 3 weeks postIYSV inoculation. Roman numerals I to IV indicate repeats of the same experiment.

$x$ Mean \pm standard error.

${ }^{y}$ Mechanical inoculation with the first plant species as the source of IYSV and the second as the inoculated plant. $\chi^{2}$ and $P>$ chi-square values are presented to indicate differences in incidence of IYSV infection in lisianthus and onion plants following mechanical inoculation with various inoculum sources, calculated using the SAS GENMOD procedure.

${ }^{\mathrm{z}} \mathrm{NE}=$ not estimated as none of the plants in both treatments was infected with IYSV or all the plants in both treatments were infected with IYSV. 
sections inoculated. IYSV infection rates were significantly greater for inoculated stem cuttings and single leaves than for leaf disks in all repeats of the experiment (Table 2). In each repeat of the experiment, IYSV infection rates were not significantly different between inoculated stem cuttings and single leaves (Table 2). The infection rates in stems ranged from 60 to $70 \%$ and in single leaves from 65 to $75 \%$. However, on leaf disks, the infection rates were three to five times less than the IYSV infection rates in stems and single leaves.

Distribution of IYSV in lisianthus plants. Sections (upper, middle, and lower leaves, and stems and roots) (Fig. 3) of whole lisianthus plants previously tested by DAS-ELISA as being infected by IYSV were each infected with IYSV. However, despite detection of IYSV infection in all the lisianthus plants used in each repeat of this experiment, IYSV was not always detected in all the plant parts tested on every plant. None of the plant parts of lisianthus plants inoculated with noninfected lisianthus leaf tissue tested positive for IYSV in all repeats of this experiment. The infection rates among plant sections differed among repeats of the experiment. In the first two repeats, IYSV infection rates among the plant parts ranged from 60.0 to $84.6 \%$ (Table 3 ). However, no significant differences in IYSV infection rates were noticed among the plant parts. In the third repeat of the experiment, IYSV infection rates ranged from 70.0 to $100.0 \%$ among the plant parts tested for IYSV (Table 3). IYSV infection rate in upper leaves was significantly greater than the infection rate in stems $\left(\chi^{2}=4.69 ; \mathrm{df}=1,18 ; P=\right.$ $0.0303)$. Likewise, the infection rate in leaves from the middle of the plants was also greater than the infection rate in stems $\left(\chi^{2}=\right.$ 4.69 ; df $=1,18 ; P=0.0303)$. In the fourth repeat of the experiment, IYSV infection rates ranged from 75.0 to $100.0 \%$ among the plant parts tested (Table 3). IYSV infection rate in upper leaves was greater than the infection rate in stems $\left(\chi^{2}=4.28 ; \mathrm{df}=1,18 ; P\right.$ $=0.0386$ ). Similarly, the infection rate in leaves from the middle of the plants was greater than the infection rate in stems $\left(\chi^{2}=4.49\right.$; $\mathrm{df}$ $=1,18 ; P=0.0340)$. Similarly, IYSV infection rate in lower leaves was also greater than the infection rate in stems $\left(\chi^{2}=4.49\right.$; $\mathrm{df}=1$, $18 ; P=0.0340)$. No differences in the incidence of IYSV infection were noticed among upper, middle, and lower lisianthus leaves in all repeats of the experiment.

Mechanical inoculation of lisianthus plants with TSWV. TSWV-inoculated lisianthus plants typically produced different symptoms than those infected with IYSV. TSWV-infected plants exhibited chlorosis, stunting, and reduction in leaf size (Fig. 4). However, necrotic spots similar to IYSV infection were also observed on TSWV-inoculated lisianthus plants in three out of four repeats of the experiment. The incidence of necrotic spots ranged from 0 to $30 \%$ and averaged $12.3 \pm 6.3 \%$ (mean \pm standard error) across all four repeats of the experiment. TSWV-induced symptoms were noticed 10 to $15 \mathrm{dpi}$. None of the control plants exhib-

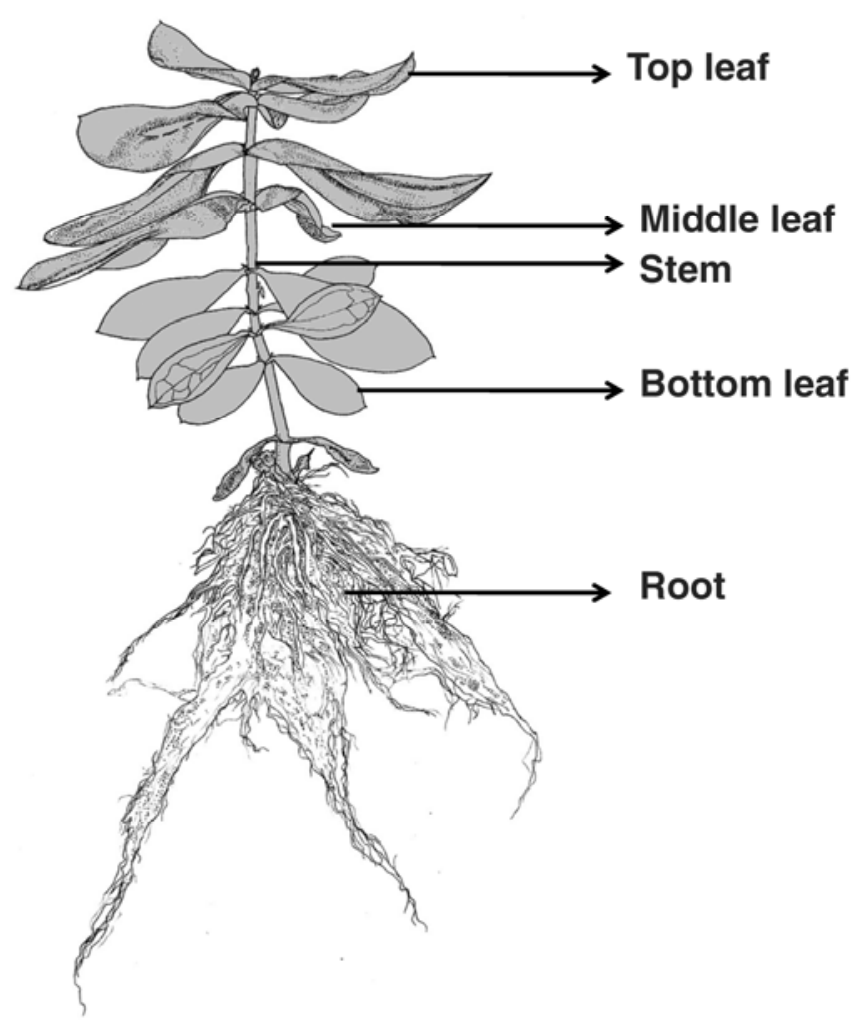

Fig. 3. Positions of a lisianthus plant from which tissue sections were removed and tested by double antibody sandwich enzyme-linked immunosorbent assay (DASELISA) for Iris yellow spot virus (IYSV) 2 to 3 weeks postinoculation. IYSV inoculations were performed mechanically as described in the text.

Table 2. Iris yellow spot virus (IYSV) transmission to lisianthus plant sections following mechanical inoculation

\begin{tabular}{|c|c|c|c|c|}
\hline \multirow[b]{2}{*}{ Plant section $y$} & \multicolumn{3}{|c|}{ Number of plant sections infected/inoculated ${ }^{\mathrm{x}}$} & \multirow[b]{2}{*}{ Incidence $(\%)$ of infected plant sections ${ }^{\mathrm{z}}$} \\
\hline & $\mathbf{I}$ & II & III & \\
\hline Stem cutting & $12 / 20$ & $14 / 20$ & $13 / 20$ & $65.0 \pm 5.0$ \\
\hline Stem cutting (control) & $0 / 20$ & $0 / 20$ & $0 / 20$ & 0 \\
\hline Single leaf & $15 / 20$ & $13 / 20$ & $15 / 20$ & $73.3 \pm 3.4$ \\
\hline Single leaf (control) & $0 / 20$ & $0 / 20$ & $0 / 20$ & 0 \\
\hline Leaf disk & $4 / 20$ & $4 / 20$ & $3 / 20$ & $18.3 \pm 1.3$ \\
\hline Leaf disk (control) & $0 / 20$ & $0 / 20$ & $0 / 20$ & 0 \\
\hline \multicolumn{5}{|c|}{ Proc GENMOD type 3 analysis: } \\
\hline \multicolumn{5}{|c|}{ Stem cutting vs. single leaf } \\
\hline$\chi^{2}$ & 1.16 & 0.15 & 0.50 & \\
\hline$P>$ chi-square & 0.2810 & 0.6973 & 0.4797 & \\
\hline \multicolumn{5}{|c|}{ Stem cutting vs. leaf disk } \\
\hline$\chi^{2}-1-10$ & 7.72 & 13.51 & 16.33 & \\
\hline$\stackrel{\sim}{P}>$ chi-square & 0.0055 & 0.0002 & $<0.0001$ & \\
\hline \multicolumn{5}{|l|}{ Single leaf vs. leaf disk } \\
\hline$\gamma^{2}$ & 14.22 & 11.10 & 11.48 & \\
\hline$\stackrel{\chi}{P}>$ chi-square & 0.0002 & 0.0009 & 0.0007 & \\
\hline
\end{tabular}

${ }^{\mathrm{x}}$ Inoculated plant sections were tested for IYSV infection by double antibody sandwich enzyme-linked immunosorbent assay (DAS-ELISA) 1 to 2 weeks post-IYSV inoculation. Roman numerals I to III indicate numbers of repeats of the same experiment.

y Plant sections were mechanically inoculated using IYSV-infected lisianthus leaf tissue. For the control treatment, lisianthus plants were inoculated with noninfected lisianthus leaf tissue, as described in the main text. Stem cuttings (approximately 5 to $7 \mathrm{~cm} \mathrm{long)} \mathrm{with} \mathrm{apical} \mathrm{buds} \mathrm{were} \mathrm{clipped} \mathrm{from} 15 \mathrm{~cm}$ tal lisianthus plants, single leaves were obtained from the upper portion of lisianthus plants, and leaf disks of $15 \mathrm{~mm}$ diameter were cut from individual leaves. $\chi^{2}$ and $P>$ chi-square values of pairwise contrasts are presented to indicate differences in the incidence of IYSV infection between plant parts calculated using the SAS GENMOD procedure.

${ }^{\mathrm{z}}$ Mean \pm standard error. 
ited these symptoms. TSWV infection was confirmed using DASELISA. The infection rates ranged from 70 to $100 \%$, and averaged $80.8 \pm 6.8 \%$ across all four repeats of the experiment.

Thrips-mediated inoculation of lisianthus plants with IYSV. Symptoms typical of IYSV infection were observed only on lisianthus plants inoculated with potentially viruliferous $T$. tabaci, and not on plants inoculated with nonviruliferous thrips. Sunken spots similar to those observed on mechanically inoculated plants were noticed 3 to 5 dpi on plants inoculated with potentially viruliferous thrips. These spots were easily distinguishable from symptoms caused by thrips feeding injury, which usually consisted of coarse stippling and silvery patches on leaf surfaces. The infection rates ranged from 60 to $100 \%$. The average rate of IYSV transmission by $T$. tabaci was $80.0 \pm 8.3 \%$ (mean \pm standard error).

Effect of diurnal temperature ranges on IYSV symptom expression in lisianthus plants. IYSV symptom development varied with different diurnal temperature ranges evaluated. For the 25 and $30^{\circ} \mathrm{C}$ diurnal temperature range, symptoms of IYSV infection were observed 3 to 5 dpi (Fig. 5). Symptom development was delayed at least 5 dpi for the 18 and $23^{\circ} \mathrm{C}$ range (Fig. 5B), but the symptoms that developed later were similar to those observed with the 25 and $30^{\circ} \mathrm{C}$ treatment. At the 30 and $37^{\circ} \mathrm{C}$ incubation temperature range, only a few necrotic spots (two to three necrotic spots/leaf compared with 20 to 30 necrotic spots/leaf at the 18 and $23^{\circ} \mathrm{C}$ or 25 and $30^{\circ} \mathrm{C}$ treatments) were noticed at $5 \mathrm{dpi}$ (Fig. 5C and D). IYSV infection rates varied with the experimental repeats (Table 4). In the first repeat of the experiment, the IYSV infection rate at 30 and $37^{\circ} \mathrm{C}$ was significantly less than at the other two diurnal temperature ranges, 18 and $23^{\circ} \mathrm{C}$ and 25 and $30^{\circ} \mathrm{C}\left(\chi^{2}=12.09 ; \mathrm{df}=2,27\right.$; $P=0.0024)$. Similar results were obtained in the third repeat of the experiment. IYSV infection rate at 30 and $37^{\circ} \mathrm{C}$ was significantly less than at the other two diurnal temperature ranges $\left(\chi^{2}=20.46\right.$; $\mathrm{df}$ $=2,27 ; P<0.0001)$. On the contrary, no significant differences in IYSV infection rates were noticed among diurnal temperature ranges in the second and fourth repeats of the experiment (Table 4). Based on these results, a diurnal temperature fluctuation of 18 and $23^{\circ} \mathrm{C}$ or 25 and $30^{\circ} \mathrm{C}$ was more optimum for IYSV symptom expression in lisianthus than the 30 and $37^{\circ} \mathrm{C}$ range. However, symptoms developed more rapidly at the 25 and $30^{\circ} \mathrm{C}$ temperature range than at the 18 and $23^{\circ} \mathrm{C}$ temperature range (data not shown).

\section{Discussion}

In this study, IYSV-inoculated lisianthus plants produced sunken spots that turned necrotic and then developed over the entire plant. These symptoms corroborate earlier reports of IYSV infection on lisianthus $(9,10,17)$. The ease of inoculation and the relatively short period required for expression of IYSV-induced symptoms indicate that lisianthus could potentially be used as an indicator host to study IYSV biology and virus-vector interactions. Compared to the most studied Tospovirus species, TSWV, IYSV is a relatively recently characterized pathogen, and IYSV-host plant-vector interactions are minimally understood $(4,23,28,30)$. IYSV most commonly infects onion $(6,23)$, but onion has been less than an ideal host to study such interactions primarily due to the lack of efficient mechanical inoculation protocols (1).

Both mechanical and thrips-mediated inoculations consistently produced typical IYSV-associated symptoms on lisianthus as early as 3 to $5 \mathrm{dpi}$ in this study. The two methods resulted in 80.0 to $89.2 \%$ transmission rates for IYSV. Mechanical inoculation of lisianthus with IYSV-infected lisianthus foliage resulted in a transmission rate that was not significantly different than that using IYSV-infected onion foliage. T. tabaci adults also transmitted IYSV efficiently from IYSV-infected onion plants to lisianthus plants. In a preliminary study, T. tabaci second instar larvae also appeared to transmit IYSV as efficiently as adults (R. Srinivasan, unpublished data). The high transmission efficiency in both life stages could be due, in part, to the fact that the larvae and adults used in these two studies were reared on IYSV-infected onion plants and, therefore, could have acquired IYSV soon after hatching. Mechanical and thrips-mediated transmission studies could, thus, routinely be conducted using lisianthus plants to assess responses of this host to IYSV strains, and to assess transmission parameters and vector competence. The various plant sections (stems, leaves, and leaf disks) of lisianthus tested in this study

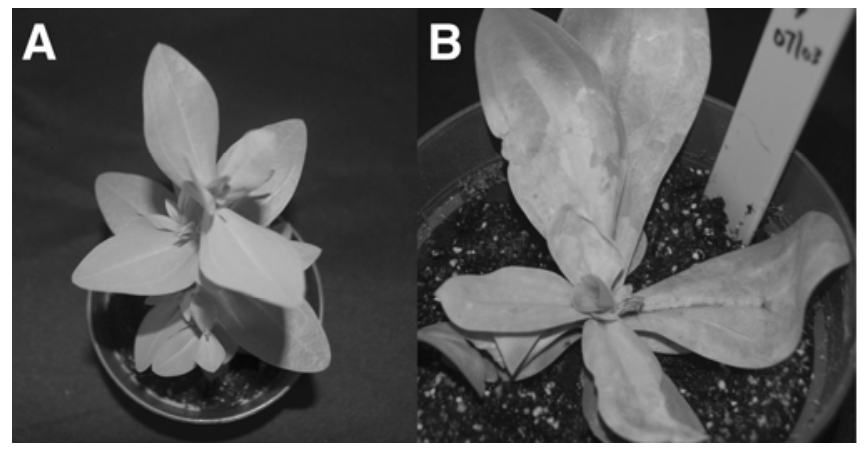

Fig. 4. Tomato spotted wilt virus (TSWV) infection of lisianthus following mechanical inoculation as described in the main text: $\mathbf{A}$, asymptomatic (noninfected) lisianthus plant; and B, TSWV-infected lisianthus plant. Symptoms were observed 10 to 15 days postinoculation.

Table 3. Distribution of Iris yellow spot virus (IYSV) in lisianthus leaves, stems, and roots following inoculation of whole lisianthus plants with IYSV

\begin{tabular}{lccccc}
\hline & \multicolumn{3}{c}{ Number of plant sections infected/tested } & \\
\cline { 2 - 4 } Plant section & I & II & III & IV & Incidence (\%) of infected plant sections $^{\mathbf{z}}$ \\
\hline Upper leaf & $8 / 10$ & $11 / 13$ & $10 / 10$ & $15 / 15$ & $91.8 \pm 5.0$ \\
Upper leaf (control) & $0 / 10$ & $0 / 13$ & $0 / 10$ & $0 / 15$ & 0 \\
Middle leaf & $6 / 10$ & $9 / 13$ & $10 / 10$ & $15 / 15$ & $82.2 \pm 10.4$ \\
Middle leaf (control) & $0 / 10$ & $0 / 13$ & $0 / 10$ & $0 / 15$ & 0 \\
Lower leaf & $7 / 10$ & $9 / 13$ & $8 / 10$ & $15 / 15$ & $79.8 \pm 7.2$ \\
Lower leaf (control) & $0 / 10$ & $0 / 13$ & $0 / 10$ & $0 / 15$ & 0 \\
Stem & $6 / 10$ & $8 / 13$ & $7 / 10$ & $12 / 15$ & $68.0 \pm 4.6$ \\
Stem (control) & $0 / 10$ & $0 / 13$ & $0 / 10$ & $0 / 15$ & 0 \\
Root & $6 / 10$ & $8 / 13$ & $9 / 10$ & $13 / 15$ & $74.8 \pm 8.0$ \\
Root (control) & $0 / 10$ & $0 / 13$ & $0 / 10$ & $0 / 15$ & 0 \\
Proc GENMOD type 3 analysis: IYSV infection in plant sections & & & \\
$\chi^{2}$ & 1.50 & 2.38 & 7.97 & 9.81 & \\
$P>$ chi-square & 0.8271 & 0.0665 & 0.0928 & 0.0438 & \\
\hline
\end{tabular}

${ }^{x}$ Plant sections were tested for IYSV infection by double antibody sandwich enzyme-linked immunosorbent assay (DAS-ELISA) 2 to 3 weeks post-IYSV inoculation. Roman numerals I to IV indicate repeats of the same experiment.

${ }^{y}$ Sections of lisianthus plants mechanically inoculated with IYSV. Whole plants were inoculated using IYSV-infected lisianthus leaf tissue as described in the main text. For the control treatment, lisianthus plants were inoculated with noninfected lisianthus leaf tissue. $\chi^{2}$ and $P>$ chi-square values are presented to indicate differences in the incidence of IYSV infection among lisianthus plant sections following mechanical inoculation calculated using the SAS GENMOD procedure.

${ }^{\mathrm{z}}$ Mean \pm standard error. 
showed typical IYSV symptoms upon mechanical inoculation. IYSV infection rates in plant sections, especially stem cuttings and single leaves, were comparable to the infection rates with whole lisianthus plants. These results indicate that lisianthus could be useful in assessing thrips-virus interactions in a similar fashion to P. hybrida-based bioassays for TSWV and INSV $(32,33)$. $P$. hybrida-based and other leaf disk-based tests have been instrumental for understanding TSWV-thrips and INSV-thrips interactions $(18,19,32,33)$. Currently, no such assay is available for IYSV, to our knowledge, and lisianthus could be used to address similar questions pertaining to IYSV.

Tospovirus infection and symptom expression can be affected by environmental factors, particularly temperature. A number of studies have been conducted to evaluate the effect of temperature on TSWV and INSV infection and symptom expression; in general, high temperatures favored Tospovirus infection $(11,12,25,26)$. Roggero et al. (25) studied the effect of temperature on INSV infection in three host plants, $C$. annuum, Capsicum chinense (Jacq.), and $N$. benthamiana. At a diurnal incubation range of 18

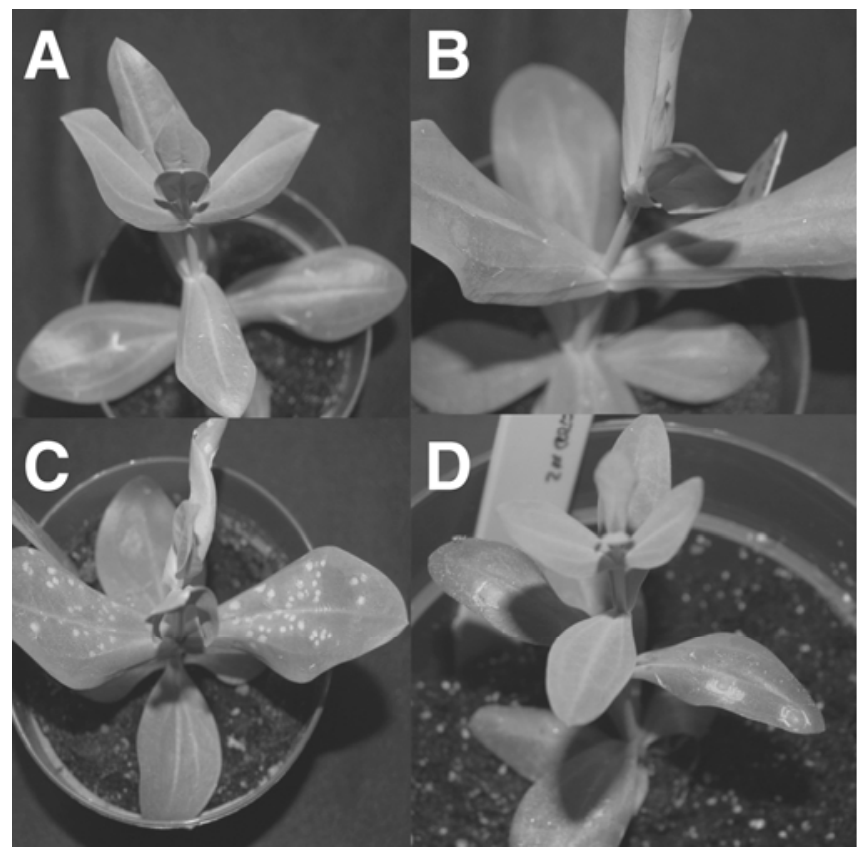

Fig. 5. Iris yellow spot virus (IYSV) symptom expression at various alternating night and day temperature ranges: $\mathbf{A}$, control plant (no virus infection); $\mathbf{B}$, inoculated plant incubated at 18 and $23^{\circ} \mathrm{C} ; \mathrm{C}$, inoculated plant incubated at 25 and $30^{\circ} \mathrm{C}$; and $\mathrm{D}$, inoculated plant incubated at 30 and $37^{\circ} \mathrm{C}$. IYSV inoculations were performed mechanically as described in the text. Photos were taken 5 days postinoculation. and $25^{\circ} \mathrm{C}$, INSV infection was systemic in all three hosts. However, with continuous exposure to $33^{\circ} \mathrm{C}$, systemic INSV infection was noticed only in $N$. benthamiana. In another study, increased INSV accumulation in $N$. benthamiana was observed at a diurnal temperature range of 26 and $33^{\circ} \mathrm{C}$ compared to 18 and $25^{\circ} \mathrm{C}(24)$. These studies reiterate that high temperatures may be favorable for Tospovirus infection, but prolonged exposure to temperatures $>30^{\circ} \mathrm{C}$ may not be favorable for systemic infection. Mandal et al. (15) also evaluated the effect of temperature ranges on TSWV infection in peanut (Arachis hypogaea L.). They observed localized ring spots on peanut plants following inoculation and incubation at a diurnal temperature range of 30 and $37^{\circ} \mathrm{C}$, and systemic infection at 25 and $30^{\circ} \mathrm{C}(15)$. Those findings underscore the need to conduct studies on tospoviruses under specific temperatures for attaining reproducible results. This study tested the effect of three different diurnal temperature ranges on IYSV infection of lisianthus. IYSV-induced necrotic spots followed by systemic infection were detected at a diurnal temperature fluctuation of 25 and $30^{\circ} \mathrm{C}$, but at a lower temperature range of 18 and $23^{\circ} \mathrm{C}$ the symptom expression was delayed by at least 5 days, even though the symptoms were similar. The rate of IYSV infection of lisianthus was significantly reduced at 30 and $37^{\circ} \mathrm{C}$ compared to the two lower diurnal temperature ranges evaluated, suggesting that prolonged exposure to high temperatures $\left(>30^{\circ} \mathrm{C}\right)$ may not be favorable for IYSV infection in lisianthus. Moreover, the symptoms were not as severe at the higher temperature range, suggesting that high temperatures could have an inhibitory effect on IYSV replication and movement in lisianthus. Mandal et al. (15) speculated that localized ring spots from TSWV infection of peanut at higher temperatures compared to systemic infection symptoms observed at lower temperatures were because higher temperatures restricted TSWV movement. Currently, there is no information published on the effect of temperature on IYSV expression in lisianthus, but the results of this study suggest that high temperatures $\left(>30^{\circ} \mathrm{C}\right)$ could affect IYSV symptom development in lisianthus, as for TSWV in peanut and INSV in pepper.

Generally, IYSV-induced symptoms observed on lisianthus were different from those caused by TSWV. Typically, leaf chlorosis was observed on TSWV-infected plants instead of the necrotic spots induced by IYSV. However, necrotic spots were also observed on $12.3 \%$ of the TSWV-infected plants. This suggests that symptoms caused by different tospoviruses may overlap, and care must be taken not to misdiagnose symptoms caused by IYSV versus other tospoviruses on lisianthus. The susceptibility of lisianthus to other tospoviruses besides the two tested in this study is not known.

This study indicates that lisianthus is an appropriate host to conduct IYSV studies in the laboratory, in the greenhouse, and/or in the field. Lisianthus plants can readily be obtained from commercial outlets in the United States and are relatively easy to grow (8).

Table 4. Iris yellow spot virus (IYSV) transmission to lisianthus plants at various diurnal temperature ranges following mechanical inoculation

\begin{tabular}{lccccc}
\hline & \multicolumn{3}{c}{ Number of plant sections infected/inoculated $^{\mathbf{x}}$} & \\
\cline { 2 - 4 } Diurnal temperature range $^{\mathbf{y}}$ & $\mathbf{I}$ & II & III & IV & Incidence (\%) of infected plants $^{\mathbf{z}}$ \\
\hline 18 and $23^{\circ} \mathrm{C}$ & $9 / 10$ & $9 / 10$ & $10 / 10$ & $4 / 10$ & $80.0 \pm 13.5$ \\
18 and $23^{\circ} \mathrm{C}$ (control) & $0 / 10$ & $0 / 10$ & $0 / 10$ & $0 / 10$ & 0 \\
25 and $30^{\circ} \mathrm{C}$ & $10 / 10$ & $10 / 10$ & $10 / 10$ & $6 / 10$ & $90.0 \pm 10.0$ \\
25 and $30^{\circ} \mathrm{C}$ (control) & $0 / 10$ & $0 / 10$ & $0 / 10$ & $0 / 10$ & 0 \\
30 and $37^{\circ} \mathrm{C}$ & $4 / 10$ & $10 / 10$ & $3 / 10$ & $3 / 10$ & $50.0 \pm 16.8$ \\
30 and $37^{\circ} \mathrm{C}$ (control) & $0 / 10$ & $0 / 10$ & $0 / 10$ & $0 / 10$ & 0 \\
Proc GENMOD type 3 analysis: Diurnal temperature ranges and IYSV infection & & & \\
$\chi^{2}$ & 12.09 & 2.34 & 20.46 & 1.92 & \\
$P>$ chi-square & 0.0024 & 0.3106 & $<0.0001$ & 0.3831 & \\
\hline
\end{tabular}

${ }^{\mathrm{x}}$ Inoculated plants were tested for IYSV infection by double antibody sandwich enzyme-linked immunosorbent assay (DAS-ELISA) 2 to 3 weeks postIYSV inoculation. Roman numerals I to IV indicate repeats of the same experiment.

${ }^{y}$ Mechanical inoculation and incubation of lisianthus plants at various diurnal temperature ranges. Inoculations were performed using IYSV-infected lisianthus leaf tissue. For the control treatment, lisianthus plants were inoculated with noninfected lisianthus leaf tissue. $\chi^{2}$ and $P>$ chi-square values are presented to indicate differences in the incidence of IYSV infection at various diurnal temperature ranges following mechanical inoculation calculated using the SAS GENMOD procedure.

${ }^{\mathrm{z}}$ Mean \pm standard error. 
The small size and slow growth of this plant allows the plants to be enclosed in relatively small, thrips-proof cages, which is critical for performing experiments on virus-thrips relations. Lisianthus plant sections can also be inoculated with IYSV. This provides a very high degree of flexibility to conduct studies with IYSV. Given the fact that onion is the most economically important crop that is infected by IYSV, it would be appropriate to conduct studies using onion plants. However, it is difficult to experimentally (mechanically) infect onion plants, as discussed above. An indicator host, such as lisianthus, could be useful to conduct experiments pertaining to evaluation of virus-vector interactions and virus-host plant interactions. However, extreme care should be taken not to extrapolate the results obtained using lisianthus to onions, as host plants can differentially influence thrips, tospoviruses, and their interactions $(14,25,32)$.

Besides improving our understanding of virus-vector interactions, lisianthus can be useful to monitor disease incidence from an epidemiological standpoint. Indicator hosts such as P. hybrida have been used as sentinel plants in agricultural settings to monitor the initial incidence of TSWV and assess inoculum pressure (7). Similarly, lisianthus can also potentially be used as sentinel plants in greenhouses or onion seed beds to monitor IYSV infection and, therefore, prompt appropriate management measures such as insecticide applications. This could be particularly beneficial to onion seed producers, as IYSV infection in onion seed crops can be even more damaging than in bulb crops (6).

\section{Acknowledgments}

We acknowledge the technical assistance of Mr. Simmy Mckeown, Ms. Sharon Thompson, and Ms. Tiffany Wiggins. We also thank Ms. Angelika Pia Schmid Riley for the lisianthus sketch (Fig. 3) and Ms. Sara Lehnings, Speedling Inc., for providing lisianthus seedlings.

\section{Literature Cited}

1. Bag, S., and Pappu, H. R. 2009. Symptomatology of Iris yellow spot virus in selected indicator hosts. Plant Health Progress doi:10.1094/PHP-20090824-01-BR.

2. Cho, J. J., Mau, R. F. L., Hamasaki, T., and Gonsalves, D. 1988. Detection of Tomato spotted wilt virus in thrips by enzyme linked immunosorbent assay. Phytopathology 78:1348-1352.

3. Clark, M. F., and Adams, A. N. 1977. Characteristics of the microplate method of enzyme-linked immunosorbent assay for the detection of plant viruses. J. Gen. Virol. 34:475-483

4. Cortes, I., Aires, A., Pereira, A. M., Goldbach, R., Peters, D., and Kormelink, R. 1998. Molecular and serological characterization of Iris yellow spot virus, a new and distinct Tospovirus species. Phytopathology 88:12761282.

5. Doncaster, C. P., and Davey, A. J. H. 2007. Analysis of Variance and Covariance: How to Choose and Construct Models for the Life Sciences. Cambridge University Press, Cambridge, UK.

6. Gent, D. H., du Toit, L. J., Fichtner, S. F., Mohan, S. K., Pappu, H. R., and Schwartz, H. F. 2006. Iris yellow spot virus: An emerging threat to onion bulb and seed production. Plant Dis. 90:1468-1480.

7. Groves, R. L., Walgenbach, J. F., Moyer, J. W., and Kennedy, G. G. 2003. Seasonal dispersal patterns of Frankliniella fusca (Thysanoptera: Thripidae) and Tomato spotted wilt virus occurrence in central and eastern North Carolina. J. Econ. Entomol. 96:1-11.

8. Harbaugh, B. K. 2007. Lisianthus. Pages 645-663 in: Flower Breeding and Genetics, Issues, Challenges, and Opportunities for the $21^{\text {st }}$ Century. N. O. Andersen, ed. Springer, Dordrecht, The Netherlands.

9. Kritzman, A., Beckelman, H., Alexandrov, S., Cohen, J., Lampel, M., Zeidan, M., Raccah, B., and Gera, A. 2000. Lisianthus leaf necrosis: A new disease of lisianthus caused by Iris yellow spot virus. Plant Dis. 84:1185-1189.

10. Kritzman, A., Lampel, M., Raccah, B., and Gera, A. 2001. Distribution and transmission of Iris yellow spot virus. Plant Dis. 85:838-842.

11. Lawson, R. H., Dienelt, M. M., and Hsu, H. T. 1993. Effects of passaging a defective isolate of Impatiens necrotic spot virus at different temperatures. Phytopathology 83:662-670.
12. Llamas-Llamas, M. E., Zavaleta-Mejia, B., Gonzalez-Hernandez, V. A. Cervantes-Diaz, L., Santizo-Rincon, J. A., and Ochoa-Martinez, D. L. 1998 Effect of temperature on symptom expression and accumulation of Tomato spotted wilt virus in different host species. Plant Pathol. 47:341-347.

13. Mandal, B., Csinos, A. S., Martinez-Ochoa, N., and Pappu, H. R. 2008. A rapid and efficient inoculation of Tomato spotted wilt tospovirus. J. Virol. Methods 149:195-198.

14. Mandal, B., Pappu, H. R., Csinos, A. S., and Culbreath, A. K. 2006. Response of peanut, pepper, tobacco, and tomato cultivars to two biologically distinct isolates of Tomato spotted wilt virus. Plant Dis. 90:1150-1155.

15. Mandal, B., Pappu, H. R., Culbreath, A. K., Holbrook, C. C., Gorbet, D. W., and Todd, J. W. 2002. Differential response of selected peanut (Arachis hypogaea) genotypes to mechanical inoculation by Tomato spotted wilt virus. Plant Dis. 86:939-944.

16. Mullis, S. W., Langston, D. B., Gitaitis, R. D., Sherwood, J. L., and Csinos, A. S. 2004. First report of Vidalia onion (Allium cepa) naturally infected with Tomato spotted wilt virus and Iris yellow spot virus (family Bunyaviridae, genus Tospovirus). Plant Dis. 88:1285.

17. Mumford, R. A., Harju, V., Skelton, A., Nixon, T., Glover, R., and Daly, M. 2008. Iris yellow spot virus (IYSV) infecting Lisianthus (Eustoma grandiflorum) in the UK: First finding and detection by real-time PCR. Plant Pathol. 57:768.

18. Nagata, T., Almeida, A. C. L., Resende, R. O., and Avila, A. C. 2004. The competence of four thrips species to transmit and replicate four tospoviruses. Plant Pathol. 53:136-140.

19. Nagata, T., Inoue-Nagata, A. K., van Lent, J., Goldbach, R., and Peters, D. 2002. Factors determining vector competence and specificity for transmission of Tomato spotted wilt virus. J. Gen. Virol. 83:663-671.

20. Nault, B. A., Shelton, A. M., Gangloff-Kaufmann, J. L., Clark, M. E., Warren, J. L., Cabrera-La Rosa, J. C., and Kennedy, G. G. 2006. Reproductive modes in onion thrips (Thysanoptera: Thripidae) populations from New York onion fields. Environ. Entomol. 35:1264-1271.

21. Nischwitz, C., Pappu, H. R., Mullis, S. W., Sparks, A. N., Langston, D. R., Csinos, A. S., and Gitaitis, R. D. 2007. Phylogenetic analysis of Iris yellow spot virus isolates from onion (Allium cepa) in Georgia (USA) and Peru. J. Phytopathol. 155:531-535.

22. Pappu, H. R. 2008. Tomato spotted wilt virus (Bunyaviridae). Pages 133138 in: Encyclopedia of Virology, Vol. 5, 3rd ed. B. W. J. Mahy and M. H. V. Van Regenmortel, eds. Elsevier, Oxford, UK.

23. Pappu, H. R., Jones, R. A. C., and Jain, R. K. 2009. Global status of Tospovirus epidemics in diverse cropping systems: Success achieved and challenges ahead. Virus Res. 141:219-236.

24. Roggero, P., Adam, G., Milne, R. G., and Lisa, V. 1996. Purification and serology of virions of Impatiens necrotic spot tospovirus. Eur. J. Plant Pathol. 102:563-568.

25. Roggero, R., Dellavalle, G., Ciuffo, M., and Pennazio, S. 1999. Effects of temperature on infection in Capsicum sp. and Nicotiana benthamiana by Impatiens necrotic spot tospovirus. Eur. J. Plant Pathol. 105:509-512.

26. Roggero, P., Lisa, V., Nervo, G., and Pennazio, S. 1996. Continuous high temperature can break the hypersensitivity of Capsicum chinense 'PI 152225 ' to Tomato spotted wilt tospovirus (TSWV). Phytopathol. Mediterr. 35:117-120.

27. Sakurai, T., Inoue, T., and Tsuda, S. 2004. Distinct efficiencies of Impatiens necrotic spot virus transmission by five thrips vector species (Thysanoptera: Thripidae) of tospoviruses in Japan. Appl. Entomol. Zool. 39:71-78.

28. Tsompana, M., and Moyer, J. W. 2008. Tospoviruses. Pages 157-162 in: Encyclopedia of Virology, Vol. 5, 3rd ed. B. W. J. Mahy and M. H. V. Van Regenmortel, eds. Elsevier, Oxford, UK.

29. Ullman, D. E., Meideros, R., Campbell, L. R., Whitfield, A. E., and Sherwood, J. L. 2002. Thrips as vectors of tospoviruses. Adv. Bot. Res. 36:113140.

30. Whitfield, A. E., Ullman, D. E., and German, T. L. 2005. Tospovirus-thrips interactions. Annu. Rev. Phytopathol. 43:459-489.

31. Wijkamp, I., Almarza, N., Goldbach, R., and Peters. D. 1995. Distinct levels of specificity in thrips transmission of tospoviruses. Phytopathology 85:1069-1074.

32. Wijkamp, I., Goldbach, R., and Peters, D. 1996. Differential susceptibilities between leaf disks and plants in the transmission of Tomato spotted wilt virus by Frankliniella occidentalis to TSWV hosts and transgenic plants. J. Phytopathol. 144:355-362.

33. Wijkamp, I., and Peters, D. 1993. Determination of the median latent period of two tospoviruses in Frankliniella occidentalis, using a novel leaf disk assay. Phytopathology 83:986-991. 